\title{
Research Article,
}

\section{Impact of Chronic Cadmium Exposure on the Nephrotoxicity Sensitivity of Streptozotocin-Induced Diabetic Rats}

\author{
N'Guessan Assue Adja Julien 1,2, Adon Mousan Arsène *1, Konan Kouassi Martin ${ }^{1,2}$, Djaman Allico \\ Joseph $^{1,2}$, Dosso Mireille ${ }^{1}$ \\ ${ }^{1}$ Unité de Biologie Cellulaire, Institut Pasteur de Côte d'Ivoire (IPCI) 01 BP 490 ABIDJAN 01 \\ ${ }^{2}$ Laboratoire de pharmacodynamie biochimique, Département des biosciences, Université félixemail \\ Email Address: arsenemadon@gmail.com
}

\begin{abstract}
:
The present study aimed to assess the role of subchronic cadmium exposure in the development of diabetic nephropathy. Diabetic rats induced by streptozotocin $(\mathrm{STZ}+\mathrm{Cd})$ and normal non-diabetic rats $(\mathrm{Cd})$ were exposed to cadmium sulphate in drinking water at a dose of $200 \mathrm{mg} / 1$ for 30 days. After 30 days of cadmium poisoning, blood and tissue samples were taken to determine markers of kidney function (urea, uric acid, creatinine, total protein and inorganic ions) and for the achievement histological couples. Cadmium poisoning resulted in an increase in relative kidney weights and a change in biochemical parameters in serum. Histopathological examination of the kidneys revealed degeneration and necrosis of the renal tubules and shrinking of the glomeruli in rats poisoned with $\mathrm{Cd}$. However, our results showed that diabetic rats induced by streptozotocin are more sensitive to nephrotoxicity of cadmium than rats normal. Our results suggest that cadmium may be a factor in the development of diabetic nephropathy.
\end{abstract}

Key words: diabetes mellitus; Diabetic nephrotoxicity; Cadmium

\section{Interoduction:}

Cadmium (Cd) is a naturally occurring nonessential toxic heavy metal that is widely distributed in the earth's crust. It has many industrial applications, use in several alloys, color pigments, electroplating, and rechargeable nickelcadmium batteries [1]. In mammals, the major sources of $\mathrm{Cd}$ exposure are contaminated water and food, cigarette smoke, and industrial pollutants [2]-[3]. Cd content in human can gradually increase by exposure to $\mathrm{Cd}$-contaminated foods, which is through bio-accumulated effects raising $\mathrm{Cd}$ levels in the food chain (such as 0.06 $\mathrm{mg} / \mathrm{L}$ vs. $0.42-0.63 \mathrm{mg} / \mathrm{L}$ of $\mathrm{Cd}$ in rice from nonvs. Cd-contaminated areas), and may cause a higher incidence of many Cd-related diseases, including renal dysfunction, hepatotoxicity, osteoporosis, and cancers [4]-[5]. Recent epidemiological studies suggest a positive association between exposure to environmental $\mathrm{Cd}$ and the incidence and severity of diabetes [6]. The diabetic patient can easily receive the $\mathrm{Cd}$ from these any one of the ways from the environment which leads to subsequent progression and development of early stage of diabetic nephropathy. One of the most serious complications of diabetes is chronic kidney disease, also known as diabetic nephropathy. Diabetic nephropathy is associated with albuminuria, decreased creatinine clearance, altered glomerular morphology and tubular degeneration [7]. Approximately 30-40\% of type II diabetic patients will develop diabetic nephropathy, and it is now the most common cause of end stage renal failure in the Western world [7][8]. The renal injury in diabetic nephropathy is due to a series of complex pathophysiological changes such as glomerulosclerosis, vascular diseases and changes of the tubulointerstitium with tubular atrophy and interstitial fibrosis initiated by disturbed glucose homeostasis [9]. While diabetic nephropathy is most commonly associated with the more severe and advanced stages of type II diabetes, there is increasing concern that even early 
stages of the disease, which are sometimes referred to as prediabetes, may be associated with increased risk of kidney disease. Diabetic nephropathy is clearly chronic progressive diseases that are associated with a combination of genetic, lifestyle and environmental factors. While many risk factors have been identified, such as obesity, diet and other lifestyle factors, it is highly likely that there are as yet unidentified environmental factors that influence whether mild or incipient diabetes progresses to a more advanced disease state. In this context, the growing volume of evidence suggesting that $\mathrm{Cd}$ may play a role in the development and progression of diabetes and diabetes-related kidney disease could be especially significant.

The purpose of this study is to assess the effect of cadmium on the severity and manifestations of diabetes.

\section{Materials and methods:}

Animals and treatment: Twenty young male Wistar rats weighting between 209- $279 \mathrm{~g}$ were obtained from the Ecole Normale Supérieure d'Abidjan animal facility. These animals were housed at the Pasteur Institute animal care facility in plastic cages and a cycle of day/night was maintained (approximately 12 hours of light and 12 hours of darkness) in a ventilated animal room. The rats were acclimated for 14 days to their new environment before the treatment and had free access to sterile distilled water and sterilized standard food. All the animals were handled in accordance with the guidelines and protocols approved by the Care and Use of Animals Committee of Côte d'Ivoire. Diabetes mellitus was induced in rats after one day fasting by intraperitoneal injection of a single dose of $60 \mathrm{mg} /$ $\mathrm{kg}$ of body weight of streptozotocin (STZ) (Cayman Chemical, Michigan, USA) diluted in a freshly prepared citrate buffer $(0.1 \mathrm{~mol} / \mathrm{L}$, ph 4.5$)$ [10]-[11]. Blood glucose levels were measured from the tail vein using an Accu Chek Active ${ }^{\circledR}$ (Roche, GU, Germany) glucometer before and three days after the STZ injection, rats with blood glucose levels greater than $250 \mathrm{mg} / \mathrm{dl}$ were considered to be diabetic and used for experimental studies [12]-[13].The rats were divided into four experimental groups (control, STZ-treated, Cd-treated and Cd + STZ-treated), each group is made of five rats. The control and STZ-treated groups received distilled water and the Cd- and Cd + STZ-treated groups had distilled water enriched with cadmium sulphate (cdso4) at 200mg/l [14]-[15]. The experiment was conducted for 30 days and during that period. After 30 days treatment, the rats were euthanized, the blood samples were collected for biochemical assays and the pancreas quickly removed for histopatological examination.

Biochemical analysis: The blood samples collected either on heparin were centrifuged and the collected serums were sent to the clinical biochemistry laboratory of the Institute Pasteur de Côte d'Ivoire respectively for the determination of glycated hemoglobin, and the lipid profile according to their laboratory protocols.

Histological Analysis: The collected pancreas samples were immediately immersed in a $10 \%$ formalin solution and sent to the pathology laboratory of the Centre Hospitalier Universitaire (CHU) de Treichville. The fixed tissues were embedded in paraffin, sectioned at $7 \mu \mathrm{m}$, and then mounted on slides.

Statistical analysis: The statistical analyses were carried out by using the software Graph Pad Prism 5 Demo. The results are presented in the form of average \pm SEM. The test of Student and the test of Annova were used for the comparison of the averages. A value of $p<0.05$ was regarded as significant.

\section{Results:}

\section{Effect of cadmium on the relative weight of the kidneys}

Administration of $\mathrm{Cd}$ to diabetic rats for 30 days resulted in a significant increase in rat kidney weights compared to diabetic rats $(\mathrm{p}<0.01) . \mathrm{Cd}$ also increased kidney weights in non-diabetic $\mathrm{Cd}$ rats, but this increase was not significant (Figure $1)$.

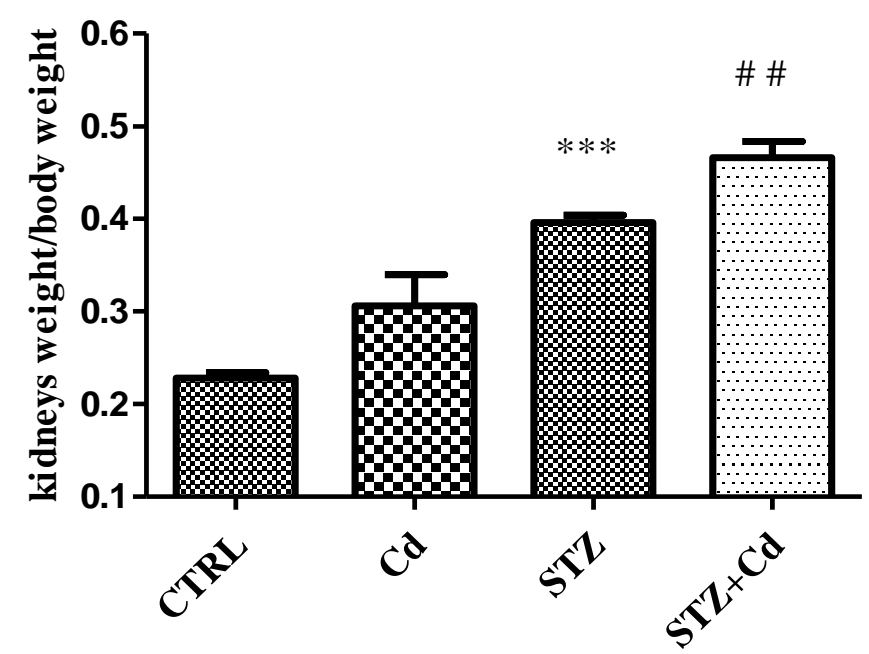

Figure 1. Kidney weight/body weight ratio of the experimental animals. Each column represents mean $\pm S D$, 
$n=5$. $* * *$ represents significant differences between the STZ treated group and normal controls $(p<0.01)$, \#\# represents significant differences between the $\mathrm{STZ}+\mathrm{Cd}$ treated group and STZ treated $(p<0.001)$

\section{Effect of cadmium on blood biochemical parameters}

Cadmium poisoning of non-diabetic rats (group $\mathrm{Cd}$ and $\mathrm{STZ}+\mathrm{Cd}$ ) caused a significant increase in the level of urea, uric acid, calcium and sodium and a non-significant decrease in the level of glucose, magnesium and total protein relative to the control groups. In diabetic rats (group $\mathrm{STZ}+\mathrm{Cd}$ ), poisoning with $\mathrm{Cd}$ resulted in a highly significant increase in serum urea, uric acid, creatinine, calcium and sodium and a significant decrease in glucose, magnesium and total protein compared to the STZ group.

Table: Effect of $\mathrm{Cd}$ on biochemical parameters in rat serum after acute exposure.

\begin{tabular}{|c|c|c|c|c|}
\hline & Ctrl & $\mathrm{Cd}$ & STZ & $\mathrm{STZ}+\mathrm{Cd}$ \\
\hline $\begin{array}{l}\text { Glucose } \\
(\mathrm{g} / \mathrm{l})\end{array}$ & $0,98 \pm 0,07$ & $0,95 \pm 0,23$ & $\begin{array}{l}7,15 \quad \pm \\
0,51^{* * *}\end{array}$ & $4,36 \pm 0,39^{\#}$ \\
\hline Urea (g/l) & $\begin{array}{l}0,17 \quad \pm \\
0,003\end{array}$ & $\begin{array}{l}0,23 \pm 0,01 \\
* *\end{array}$ & $\begin{array}{l}0,26 \pm \\
0,008^{* * * *}\end{array}$ & $0,42 \pm 0,01^{\# \#}$ \\
\hline $\begin{array}{c}\text { Creatinine } \\
(\mathrm{mg} / \mathrm{dl})\end{array}$ & $\begin{array}{l}0,40 \\
0,04\end{array}$ & $1,08 \pm 0,33$ & $\begin{array}{l}0,79 \\
0,05^{* *}\end{array} \quad \pm$ & $1,52 \pm 0,198^{\#}$ \\
\hline $\begin{array}{l}\text { Total } \\
\text { protein } \\
(\mathrm{g} / \mathrm{l})\end{array}$ & $\begin{array}{l}70,33 \quad \pm \\
2,84\end{array}$ & $\begin{array}{l}54,00 \quad \pm \\
4,72\end{array}$ & $\begin{array}{ll}81,67 \quad \pm \\
8,29\end{array}$ & $\underset{\# \#}{41,00 \pm 2,64}$ \\
\hline $\begin{array}{l}\text { uric acid } \\
(\mathrm{mg} / \mathrm{dl})\end{array}$ & $\begin{array}{l}2,18 \quad \pm \\
0,19\end{array}$ & $\begin{array}{l}3,87 \quad \pm \\
0,13^{* *}\end{array}$ & $\begin{array}{l}5,20 \quad \pm \\
0,54 * *\end{array}$ & $9,25 \pm 0,53^{\# \#}$ \\
\hline $\begin{array}{l}\mathrm{Ca} \\
(\mathrm{mg} / \mathrm{dl})\end{array}$ & $\begin{array}{l}8,33 \quad \pm \\
1,20\end{array}$ & $\begin{array}{l}15,33 \\
1,20^{*}\end{array}$ & $\begin{array}{l}40,67 \\
2,72 * * *\end{array} \quad \pm$ & $75,67 \pm 6,00^{\#}$ \\
\hline $\begin{array}{l}\mathrm{Mg} \\
(\mathrm{mg} / \mathrm{dl})\end{array}$ & $\begin{array}{l}12,83 \quad \pm \\
0.44\end{array}$ & $9,66 \pm 1.30$ & $\begin{array}{l}24,71 \\
0.35 * *\end{array}$ & $20,17 \pm 1.01^{\text {\# }}$ \\
\hline $\begin{array}{l}\mathrm{Cl} \\
(\mathrm{mmol} / \mathrm{L})\end{array}$ & $\begin{array}{l}103,3 \quad \pm \\
2,963\end{array}$ & $\begin{array}{l}146,00 \quad \pm \\
2,58\end{array}$ & $\begin{array}{l}273,70 \quad \pm \\
4,48^{* *}\end{array}$ & $345,00 \pm 2,21$ \\
\hline $\begin{array}{l}\mathrm{Na} \\
(\mathrm{mmol} / \mathrm{L})\end{array}$ & $\begin{array}{l}140,7 \quad \pm \\
3,52\end{array}$ & $\begin{array}{l}217,0 \\
19,29 * \quad \pm\end{array}$ & $\begin{array}{l}361,7 \pm \\
17,89 * * *\end{array}$ & $\begin{array}{l}457,7 \\
9,387^{\# \#}\end{array} \quad \pm$ \\
\hline
\end{tabular}

\section{Histology:}

The photomicrograph of the renal tissues stained with hematoxylin-eosin of the groups of control and experimental rats is represented in Figure 2A to 2D. Control rats (CTRL) have glomeruli and normal tubular structures (Figure 2A). The renal tissue of non-diabetic rats exposed to $\mathrm{Cd}$ and diabetic rats (STZ), showed a slight tubular degeneration with glomerular involvement (Figure $2 \mathrm{~B}$ and $2 \mathrm{C}$ ). The renal tissue of diabetic rats treated with cadmium (STZ + Cd), showed tissue disorganization marked by necrotic glomeruli with degenerate tubules (Figure 2D).

\section{Discussion:}

In the present study, cadmium was administered orally to rats since it was the main route of exposure for the general population [16]. Our results demonstrated that rats with streptozotocininduced diabetes were more sensitive to the effects of subchronic cadmium exposure in drinking water compared to non-diabetic rats.

The ingestion of cd caused a significant increase in the absolute weight of the kidneys of diabetic rats. This enlarged kidney is caused by an intense buildup of cadmium in the kidneys which causes kidney damage and reduced glomerular filtration. The $\mathrm{Cd}-$ induced organomegaly has been associated with inflammation processes, triggered by this metal [17]. Analysis of the results showed a decrease in total protein in diabetic and non-diabetic rats contaminated with cadmium. This reduction can be explained by the fact that most proteins have groups $(\mathrm{SH}, \mathrm{OH})$. The latter react very easily with cadmium and the free radicals generated by this metalloid, and as a result, these proteins can denature and fragment, or lose their structures. In addition, the exposure of rats to $\mathrm{Cd}$ can modify the metabolism of proteins and amino acids and their synthesis in the liver [18]. Kidneys play vital role in the excretion of metabolic wastes including urea, uric acid, and creatinine. Hence, alteration in the levels of urea, creatinine, and uric acid in serum, as well as urine, reflected renal dysfunction [19] - [20]. These substances are normal metabolic waste products that are excreted by the kidneys. Urea is a byproduct of protein breakdown. Serum creatinine is primarily a metabolite of creatine and uric acid is an end product of purine metabolism that is produced mainly by the liver and intestines. In kidney disease, these substances are not excreted normally, and so they accumulate in the body thus causing an increase in blood levels of urea. Our study also showed that elevated the high levels of creatinine, urea and uric acid (Table 1) along with renal proximal tubular injury and narrowing of arterial wall thickening and focal interstitial nephritis with glomeruli mesangial capillary proliferation with tubular epithelial 
damage (Figure.2) in STZ-Cd treated rats due to the lack of insulin secretion from the pancreatic $\beta$ cells along with prolonged accumulation of $\mathrm{Cd}$ in tubular epithelial and pancreatic $\beta$-cells [21].

Impaired excretory function is also supported by the fact that levels of some serum ions have been changed $(\mathrm{Ca}, \mathrm{Mg}, \mathrm{P}$, and $\mathrm{Cl}) . \mathrm{Cd}$ and essential metals can interact by influencing each other's rates of absorption, retention, distribution and bioavailability in the body. This is mainly because of their competition for the same binding sites, especially - $\mathrm{SH}$ groups, in various enzymes and other metalloproteins such as metallothionein (MT) [22]. Many investigators have shown that $\mathrm{Cd}$ is able to induce a perturbation in calcium homeostasis [23] - [24]. Cd inhibits the pathways of cellular calcium influx and acts as a competitive ion to calcium at the voltage dependent $\mathrm{Ca}^{2+}$ channels [25]. The inhibition of transcellular calcium transport takes place at the basolaterally located $\mathrm{Ca}^{2+}$ pumps in the membrane proteins involved in the $\mathrm{Na}+/ \mathrm{Ca} 2+$ exchanger [26], which is dependent on the correct operation of $(\mathrm{Na}+$ and $\mathrm{K}+$ )-atpase, and the $\mathrm{Ca}^{2+}-$ atpase. As it was mentioned before, in our study, the present data showed that the cells extracted from the treated rats have a significant increase in intracellular calcium and decrease in intracellular sodium in rats treated with cadmium chloride. Lower blood Mg levels, generally thought to be a result of $\mathrm{Cd}$ exposure, could be explained by an increased $\mathrm{Cd}$ level in the gut, induced by mucociliar transfer, by bile elimination or by excretion of $\mathrm{Cd}$ through the intestine walls [27], which in turn may cause an inhibition of $\mathrm{Mg}$ absorption in gut, thus leading to a decrease of blood $\mathrm{Mg}$. The other possibility is that $\mathrm{Mg}$ from blood moves to target organs and tissues as a consequence of organism system defense against $\mathrm{Cd}$ toxicity

\section{Conclusion:}

Our study showed that sub acute exposure of diabetic rats to the dose of $200 \mathrm{mg} / 1$ in drinking water influenced the development of diabetic nephropathy.

\section{Acknowledgements:}

We thank Pasteur Institute of Cote d'Ivoire (IPCI) and the Centre Hospitalier Universitaire (CHU) de Treichville.

Conflict of Interest: The authors state that they have no financial interest and no conflict of interest.

\section{References:}

[1] Jarup L (2003). Hazards of heavy metal contamination. Br Med Bull 68: 167-182.

[2] Bernard A (2008). Cadmium \& its adverse effects on human health. Indian $\mathrm{J}$ Med Res 128: 557-564.

[3] IPCS (1992). Environmental Health Criteria 134. Cadmium. World Health Organization, Geneva.

[4] Inaba T, Kobayashi E, Suwazono Y, Uetani M, Oishi M, et al. (2005). Estimation of cumulative cadmium intake causing Itai-itai disease. Toxicol Lett 159: 192-201.

[5] WHO (1993). Evaluation of certain food additives and contaminants. Forty-first Report of the Joint FAO/WHO Expert Committee on Food Additives. WHO Technical Report Series 837.

[6] Edwards J. and Prozialeck W. (2009). Cadmium, diabetes, and chronic kidney disease. Toxicol Appl Pharmacol 238:289293.

[7] Schrijvers BF, De Vriese AS, and Flyvbjerg A. (2004). From hyperglycemia to diabetic kidney disease: the role of metabolic, hemodynamic, intracellular factors and growth factors/cytokines. Endocr.Rev; 25:971-1010.

[8] USRDS (United State Renal Data System), 2003. USRDS 2003 Annual Data Report: Atlas of End-Stage Renal Disease in the United States, National Institute of Health, National Institute of Diabetes and Digestive and Kidney Diseases. Bethesda, MD.

[9] Dalla Vestra, M., Saller A., Bortolosco E., Mauer M., and Fioretto P., (2000). Structural involvement in type 1 and type 2 diabetic nephropathy. Diabetes Metab. 26, 8-14.

[10] Akbarzadeh A., Norouzian D., Mehrabi R., Jamshidi H., Farhangi A. And Allah V., Indian Journal of Clinical Biochemistry. 2007, 22 (2), 60-64.

[11] Daisy P., Feril G. And Kani J. (2012). Int J Pharm Sci.4 (4), 312-318.

[12] Faiyaz A. And Asma U. (2008). Global Journal of pharmacologie. 2(3), 41-45.

[13] Daisy P., Feril G. And Jeeva K. (2013). Asian J. Pharm. Clin. Res., 6(2), 43- 48.

[14] Naima L. And Zine K. (2012). African Journal of Biotechnology. 11(93), 1601316020 . 
[15] Babatunji O., Basiru A., Oluwaf A., Sarah O. And Abidemi P. (2016). Pharmacognosy Magazine. 12(12), 170-174.

[16] SAYSTAT (1987). Guide for Personal Computers, 6th edn. The SAS Institute Inc., Cary, NC.

[17] Donpunha W,Kukongviriyapan U, Sompamit K,Pakdechote P,Kukongviriyapan V, Pannangpetch P. (2011). Protective effect of ascorbic acid on cadmium-induced hypertension and vascular dysfunction in mice. Biometals 24: 105-15

[18] El-Demerdash F., Yousef M., Kedwany F, and Baghdadi H. (2004). Role of $\alpha$-tocopherol and b-carotene in ameliorating the fenvalerate-induced changes in oxidative stress, hemato-biochemical parameters and semen quality of male rats. Journal of Environmental Science and Health. 39: 443-459.

[19] Yorek M. (2003). The role of oxidative stress in diabetic vascular and neural disease. Free Radic. Res.37: 471-480.

[20] Leehey D., Singh A., Alavi N., and Singh R. (2000). Role of angiotensin II in diabetic nephropathy. Kidney Int. 58:S93-S98.

[21] Kandasamy, Neelamegam, Ashokkumar, Natarajan (2014). Protective effect of bioflavonoid myricetin enhances carbohydrate metabolic enzymes and insulin signaling molecules in streptozotocincadmium induced diabetic nephrotoxic rats, Toxicology and Applied Pharmacology.

[22] Peraza M., Ayala-Fierro F., Barber D., Casarez E., Rael L. (1998). Effects of micronutrients on metal toxicity. Environ Health Perspect; 106 (Suppl 1): 203-16.

[23] Xu S., Pi H., Chen Y., Zhang N., Guo P., Lu Y., et al. (2013). Cadmium induced Drp1dependent mitochondrial fragmentation by disturbing calcium homeostasis in its hepatotoxicity. Cell Death Dis; 4: e540.

[24] Long G. (1997). Cadmium perturbs calcium homeostasis in rat osteosarcoma (ros 17/2.8) cells; a possible role for protein kinase c. Toxicol Lett; 91:91-97.

[25] Abnosi M. (2010). Soleimani H. Cadmium affects viability of bone marrow mesenchymal stem cells through membrane impairment, intracellular calcium elevation and DNA. Indian J Med Sci; 64:177-186.

[26] Schoenmakers T., Klaren P., Flik G., Lock R., Pang P., Bonga S. (1992). Actions of cadmium on basolateral plasma membrane proteins involved in calcium uptake by fish intestine. J Membr Biol; 127:161-172.

[27] ATSDR (1999). Toxicological profile for cadmium. Atlanta, USA: Agency for Toxic Substances and Disease Registry. 